\title{
Bed Bath Practices Among Nurses Towards the Patients Admitted in Critical Care Units: The Role of Care Complexity
}

\author{
Farhat-un-Nisa, Riffat-un-Nisa, Tallat-un-Nisa, Sumera Shareef
}

\begin{abstract}
Introduction: Every day bed-bath are normally accommodated most basically sick patients to improve their cleanliness, advance solace and improve wellbeing results. Fundamentally sick patients are at more serious hazard for skin colonization and contamination with multidrug-resistance pathogenic organisms. Hence, it is imperative to furnish basically sick patient with powerful close to home cleanliness particularly bed-bath as poor cleanliness may expand the danger of contamination. Methodology: quantitative observational descriptive study design was used to assess the nurses' practices regarding bed-bath of critically ill patients. In order to assess nurses practiced, data was collected through the standardized checklist regarding bed bath. The check consists of 51 items. Results: The findings of this study revealed that there is poor practices of nurses regarding bed bath of critically ill patients. Conclusion: This study has described an important basic nursing care that is bed-bath practice in critically ill patient. Although, bed-bath is a routine nursing procedure, critical care nurses in the current study had poor skills and practices regarding it. This study has implications for clinical practice and nursing research. Bed-bath is a routine nursing care; many nurses understand that bathing is just for cleaning. Therefore, Inservice training program should be conducted
\end{abstract}

Keywords: bed bath, practice, critical, patient.

DOI: $10.7176 / \mathrm{JHMN} / 95-02$

Publication date: November $30^{\text {th }} 2021$

\section{INTRODUCTION}

Background: Every day bed-bath are normally accommodated most basically sick patients to improve their cleanliness, advance solace and improve wellbeing results. Fundamentally sick patients are at more serious hazard for skin colonization and contamination with multidrug-resistance pathogenic organisms. Hence, it is imperative to furnish basically sick patient with powerful close to home cleanliness particularly bed-bath as poor cleanliness may expand the danger of contamination (El-Soussi \& Asfour, 2016).

There are a wide range of variables that impact and effect on our patient's cleanliness propensities and schedules. For instance, social practices and convictions, strict practices and convictions, the patients degree of development and advancement, monetary elements and financial imperatives, the customer's degree of vitality, the customer's degree of cognizance, natural variables including things like the ecological temperature and the customer's condition of vagrancy, the patients general condition of wellbeing and their own specific as far as their own cleanliness propensities (Hema Priya et al., 2017).

There are various conditions that may influence a person's capacity to keep up close to home cleanliness. Hospitalized patients, and specifically the individuals who are out of commission, may get subject to nursing staff to do their cleanliness needs. Helping patients to keep up close to home cleanliness is a basic part of nursing care. right methodology and the significance of keeping up tolerant pride and regard in clinical practice (Büyükyılmaz \& Şendir, 2017).

Acts of neglect utilized for patient bathing have been recognized as a potential wellspring of contamination. The Centers for Disease Control and Prevention reports that human services related contaminations "are a significant, yet regularly preventable, danger to quiet security." Every year in the United States, around 5\%-10\% of hospitalized patients contract a medical clinic obtained disease (Sturgeon et al., 2019)

One of the methodologies to decrease patient presentation to microorganisms during bathing is the utilization of single-utilize prepackaged, premoistened, flush free expendable washcloths rather than shower bowls. Proof recommends that the utilization of chlorhexidine gluconate showers forestalls disease and might be a valuable instrument when joined with different mediations, for example, training identified with addition and expulsion of gadgets and agendas (Noto et al., 2015).

Supporting patients to keep up their cleanliness needs while they are in emergency clinic is a central part of nursing care, yet there is almost no proof to help practice. Individual cleanliness incorporates care of the: Hair; Skin; Nails; Mouth, eyes, ears and nose, Perineal regions and Facial shaving (Ette \& Gretton, 2019).

Cleanliness and healthy skin ought to be considered as one element, as both potentially affect skin wellbeing and on patients' solace and prosperity. Elements that negatively affect skin wellbeing include: Excessive washing, especially if unforgiving items are utilized, Lack of cleanliness, causing develop of potential pathogens and expanding disease hazard (Sunley, Gallagher, Reidy, \& Dunn, 2018).

Patients have their own qualities and works on identifying with cleanliness, which medical caretakers need to consider when arranging care. For instance, a few patients may wash at night as it encourages them settle for 
the evening, while others may like to shower toward the beginning of the day. Attendants ought to likewise talk about with patients any strict and social issues identifying with individual consideration (Dougherty \& Lister, 2015). For instance, in a perfect world, Muslim patients ought to be thought about by a medical attendant of a similar sexual orientation, and Hindus may wish to wash before petition (Manderson, 2018).

All patient ought to have their own toiletries or be provided with single-persistent use things until their own toiletries can be brought into public hospital. Cleanser can adjust skin $\mathrm{pH}$, prompting dryness and skin breakdown, so it is proposed that skin-purging emollient creams ought to be used (Cowdell et al., 2020). This ought to be endorsed for singular patients, and a spoon or spatula ought to be utilized to empty the item into a dispensable pot to forestall defilement; emollients in cylinders or siphon compartments decrease this hazard. New supplies ought to be endorsed following treatment for a skin disease (Lawton, 2016).

The World Health Organization expressed that non-sterile gloves are not required routinely for washing and dressing patients. Attendants need to evaluate singular patients for danger of introduction to blood and body liquids and know about nearby arrangements for glove use (Wigglesworth, 2019). Since the expendable bath was concocted in 1994, there have been various research endeavors into the item, which have been distributed. It is likewise prescribed for basically sick patients (Groven, Zwakhalen, Odekerken-Schröder, Joosten, \& Hamers, 2017).

Problem statement: Unhygienic condition possibly perilous conditions and improve the opportunity of contamination unique in fundamentally sick patient therefor they request outstanding consideration. Bed-bathing during care of fundamentally sick patients at units are basic for the prosperity of patients. Medical caretakers are assumed as a significant job during care of patient. This consideration ought to be given by proficient and skilled practices, medical attendants following explicit rule or conventions that will decrease the event of contamination and complexities and even by this improve nature of care.

Hence, there is evidence that management and care of patient with critical illness need a unique body of knowledge and skills from a responsible multidisciplinary team member especially the nurse, and specific bedbathing guidelines should be developed for preventing infections especially the health of the patient. The actual need to do the study is to assess the practice of nurses regarding bed-bathing patient. In the context of above mention research problem, the answer will give for bellow mentioned questions through this study.

Purpose of the study: the purpose of the study is to assess the nurses' practice for bed-bathing in critically ill patients in tertiary care hospital Lahore

Research questions:

- What are the practices of nurses regarding bed bathing among critically ill patient at tertiary care hospital Lahore Pakistan?

\section{Hypothesis}

Alternative hypothesis:

- There are positive nurses' practices regarding bed bathing among critically ill patients

Null hypotheses:

- There are negative nurses' practices regarding bed bathing among critically ill patients

Conceptual definition

Practices: "The application of rules and knowledge that leads to action"(Badran, 1995)

Bed bathing: Giving a bed bath means washing someone who is in bed. A bed bath cleans the skin and helps keep the skin free of infection. It helps to relax the person being bathed and help him feel better. Let the person wash himself as much as possible (Dias, Souza, Azevedo, Andrade, \& Nery, 2016).

Operational definition

Practices: standard guidelines and personal protective equipment follow/use by nurses working in critical care unit of tertiary care hospital Lahore.

Bed bathing: bed bath is washing the critically ill patients, who is in bed and cleans the skin and helps keep the skin free of infection. It helps to relax the patients admitted in tertiary care hospital Lahore.

Variables of Study:

Independent variable;

- Practices

Dependent variable;

- Bed-bath

Objectives

- To assess the Nurses' practices for bed-bath in critically ill patients in tertiary care hospital Lahore.

Significance of the study

Patient who admitted in critical units usually are unable to clean themselves and highly susceptible to infection. Thus, the application of universal precautions protected the patients and environment from infection and restricted uses of standard guidelines regarding bed bathing to promote patient safety, wellness and decrease risk of complications. 
Nurse: subsequently, assessment level of nurses' practice about bed bathing is vital action to promote health status in the critically ill patients. In this way nurses will understand their weakness and tried to adopt standard guide line in results their knowledge and skills will be improved.

Organization: The Finding of the examination may be useful for the association to build up the methodologies to control superfluous malpractices through instructional meeting, workshop, and class, this will improve the workplace and nature of care. It will be appropriate for the administration to find a way to locate the powerless components. In results the quality of care will be improved.

Policy maker: This mindfulness will help the strategy creator to plan methodologies and set in motion to improve the workplace.

Future researcher: The aftereffect of this investigation will provide guidance to the future analyst to use this examination as a writing and direction. Moreover, study will assist them with identifying the investigation hole. The discoveries of the examination can be utilized as optional information for future research researchers.

\section{MATERIAL AND METHODS}

Study Design:

Observational descriptive design was use to assess the nursing practice, Nurses' Practice for bed-bathing in critically ill patients in tertiary care hospital Lahore

Study site:

The study was conducted at Punjab institute of cardiology hospital located at urban area of Lahore, Pakistan.

Study Setting:

The study was conducted at critical care units.

Study Duration:

The Study duration was 4 months from February, 2020 to May, 2010.

\section{Study Population:}

The study population was all registered nurses working in critical care units of selected hospital.

Inclusion Criteria:

- All registered nurses working in critical care units for at least six months before the start of data collection.

- Willing to participate

Exclusion Criteria:

- Nurses working in critical care units, who were not involved in direct patient care e.g., Head nurses, Clinical Instructors and Nurse Managers and nurses who have worked for less than six months in the critical care units.

- $\quad$ Not willing to participate

Sampling Technique:

Data will be collected by convenient sampling technique from selected sample.

Sample Size:

Sample size was be calculated by using "Selvin's formula".

$\mathrm{N}=\mathrm{N} / 1+(\mathrm{N}) €^{2}$

The total population is 245 .

$\mathrm{N}=$ Population, $\mathrm{n}=$ Sample size, $\quad \mathrm{E}=5 \%$ Margin of error $\quad$ Confidence interval $95 \%$

$$
\begin{aligned}
& n=N / 1+(N) €^{2} \\
& n=245 / 1+(245)(0.05)^{2} \\
& n=245 / 1+(245)(0.0025) \\
& n=245 / 1+.61 \\
& n=245 / 1.61 \\
& n=151
\end{aligned}
$$

The sample size for this study was 151 .

\section{Ethical Consideration;}

Written permission was taken from the Ethical committee of Shalimar college of nursing. Permission was taken from the Nursing manager of Punjab institute of cardiology to conduct research study. All participants will be informed about the purpose of the study. All information and collected data were kept confidential by principal investigator hard copy in lock. Confidentiality of soft copy was maintained by a coding. The subject was informed that there are no disadvantages or risk on the procedures of the study.

\section{Data collection procedure:}

After approval observe the nurse's practices over a period of 02 months starting from march 2020 to April 2020. The selected critical units were visited on daily basis and nurses were approached during morning, evening and night shifts. 
Data Collection Instrument and Tools:

A well-adapted bed-bath check list was used to measure the practices of nurses in this study and it consists of two sections.

Section A: section A consists of demographic data such as gender, age, type of the unit, length of stay (days) and history of hospitalization.

Section B: section "B" consists of 51 items. It was used to assess the practices of nurses regarding bed-bath among critically ill patient.

\section{Data Analysis Method:}

The study was analyzing the data by SPSS version 16 . Statistical analysis of the study was descriptive. The study sample was characterized by using a measure of central tendency (mean, median, and mode).

\section{RESULTS}

This study is conducted at Panjab institute of cardiology hospital to assess the nurses' practices regarding bedbath of critically ill patients. The result of this study distributed into two sections, first section is statistics of demographic factors and second is frequency and statistics of checklist items.

Table 1 shows that the frequency of demographics includes age, experience, department, qualification and duty shift of the participants of 151 nurses and the results revealed that the age of participants was found minimum 21 to highest 60, participant's age group 21-30 years frequency was 42 (27.8\%), majority 49 (32.5\%) participants were belonging to age group 31-40 years and moderately 37 (24.5\%) were fall in age group 41- 50 years and only $23(15.2 \%)$ were 51-60-year-old. Only $23(15.2 \%)$ participants have experience $10-12$ years, majority of nurses $46(30.8 \%)$ have 4-6 years job experience and $40(26.8 \%)$ have 1-3 years' experience and 42 $(27.2 \%)$ nurses have 7-9 years' experience. Participants' department as expected was only $65(43 \%)$ working in critical care units and majority $86(57.0 \%)$ working in general wards. The qualification of the participants was found as $35(23.2 \%)$ diplomas in midwife, majority $56(37.1 \%)$ diploma in general nursing, $41(27.2 \%)$ were hold a degree of post RN BSN and only 19 (12.6\%) were bachelor of science in nursing (Generic). Observation of nurse's practices was performed in three shifts and frequency is as morning, night $50(33.1 \%)$ respectively and evening is $51(33.8 \%)$.

\section{Demographics factors frequency}

Table 1

\begin{tabular}{|l|l|c|c|}
\hline \multicolumn{1}{|c|}{ Demographic Variable } & Frequency & Valid Percent \\
\hline Age: & $21-30$ years & 42 & $27.8 \%$ \\
& 31-40 years & 49 & $32.5 \%$ \\
& 41-50 years & 37 & $24.5 \%$ \\
& $51-60$ years & 23 & $15.2 \%$ \\
& Total & $\mathbf{1 5 1}$ & $\mathbf{1 0 0 . 0} \%$ \\
\hline Department: & Medical ward & 86 & $57.0 \%$ \\
& Critical care units & 65 & $43.0 \%$ \\
& Total & $\mathbf{1 5 1}$ & $\mathbf{1 0 0 . 0} \%$ \\
\hline Qualification: & Diploma in midwifery & 35 & $23.2 \%$ \\
& Diploma in general nursing & 56 & $37.1 \%$ \\
& Bachelor of science in nursing (Post RN) & 41 & $27.2 \%$ \\
& Bachelor of science in nursing (Generic) & 19 & $12.6 \%$ \\
& Total & $\mathbf{1 5 1}$ & $\mathbf{1 0 0 . 0} \%$ \\
\hline Experience: & $1-3$ & 40 & $26.8 \%$ \\
& 4-6 & 46 & $30.8 \%$ \\
& 7-9 year & 42 & $27.2 \%$ \\
& 10-12 year & 23 & $15.2 \%$ \\
& Total & $\mathbf{1 5 1}$ & $\mathbf{1 0 0 . 0} \%$ \\
\hline Duty shift & Morning & 50 & $33.1 \%$ \\
& Evening & 51 & $33.8 \%$ \\
& Night & 50 & $33.1 \%$ \\
& Total & $\mathbf{1 5 1}$ & $\mathbf{1 0 0 . 0} \%$ \\
\hline
\end{tabular}

\section{Table 1}

Table 2 shows that the frequency of timing of bathing, number of baths per shift and duration of bath and the results revealed that the timing of bathing was $50(33.1 \%)$ in night shift at $6 . \mathrm{a} . \mathrm{m}, 51(33.8 \%)$ in evening at 6.p.m and $50(33.1 \%)$ in morning shift at 1.p.m. Only $1(0.7 \%)$ participants given 2-time bath in a shift, no one 0 $(0 \%)$ gave three time and majority $150(99.0 \%)$ given 1-time path to the patients in his /her shift. Majority of nurses $79(52.2 \%)$ take $15-20$ min while given path to the admitted patient, $29(25.8 \%)$ take $<15$ min and only $33(21.9 \%)$ take $<15 \mathrm{~min}$. 
Frequency, timing and duration bed-bat Table 2

\begin{tabular}{|c|c|c|c|}
\hline \multicolumn{2}{|c|}{ Variable } & Frequency & Valid Percent \\
\hline & 6.a.m & 50 & $33.1 \%$ \\
\hline & 6.p.m & 51 & $33.8 \%$ \\
\hline IImıng of bathıng & 1.p.m & 50 & $33.1 \%$ \\
\hline & Total & 151 & $100.0 \%$ \\
\hline & 1 time & 150 & $99.3 \%$ \\
\hline Frequency & 2 time & 1 & $0.7 \%$ \\
\hline bathing/day & 3 time & 0 & $0 \%$ \\
\hline & Total & 151 & $100 \%$ \\
\hline & $<15$ & 39 & $25.8 \%$ \\
\hline Duration/minutes & $15-20$ & 79 & $52.3 \%$ \\
\hline Duration/minutes & $<15$ & 33 & $21.9 \%$ \\
\hline & Total & 151 & 100.0 \\
\hline
\end{tabular}

Table 3 shows the mean, median, mode and standard deviation of demographic variable the highest mean 2.32 for duty shift, then 2.29 for qualification and 2.00 for Frequency of bathing/day and Experience respectively and the Timing of bathing lowest mean was 1.01. The Std. Deviation is $(1.032, .497, .963, .816$, $1.029, .081, .816, .692)$ were respectively for, age, Department, Qualification, experience, Duty shift, Timing of bathing and Duration/minutes

\section{Demographics factors Statistics}

Table 3

\begin{tabular}{|l|c|c|c|c|c|}
\hline \multicolumn{1}{|c|}{ Variable } & N & Mean & Median & Mode & $\begin{array}{c}\text { Std. } \\
\text { Deviation }\end{array}$ \\
\hline Age: & 151 & 2.27 & 2.00 & 2 & 1.032 \\
\hline Department: & 151 & 1.43 & 1.00 & 1 & .497 \\
\hline Qualification: & 151 & 2.29 & 2.00 & 2 & .963 \\
\hline Experience: & 151 & 2.00 & 2.00 & 2 & .816 \\
\hline Duty shift: & 151 & 2.32 & 2.00 & 2 & 1.029 \\
\hline Timing of bathing: & 151 & 1.01 & 1.00 & 1 & .081 \\
\hline Frequency of bathing/sift: & 151 & 2.00 & 2.00 & 2 & .816 \\
\hline Duration/minutes: & 151 & 1.96 & 2.00 & 2 & .692 \\
\hline
\end{tabular}

Section 2 consist of checklist regarding bed bathing consisting 51 items. This checklist further divided into 2 parts, and each part consists 26 and 25 items respectively.

Table 4 shows the frequency percentage of 26 items of checklist regarding bed-bathing and results revealed that mostly above $50 \%$ nurses have good practices and follow the standard guideline for bed bathing of admitted patient. Further the observation revealed that the nurses, have different level of education and also working in different department such as ward or critical care unit is varying to each other, such as the observation regarding first item of checklist and results revealed that the $75(49.7 \%)$ were observed as gather necessary equipment and $76(50.3 \%)$ were not observed while giving bed bath to the patients. The observation regarding item two which is "Wash your hands. Put on gloves" and results revealed that majority $83(55 \%)$ were observed and $68(45 \%)$ were not observed.

The results of item three were $71(47 \%)$ were observed and majority $80(53 \%)$ not observed as explaining procedure to the patient while going to give bath to the admitted patients. It was also observed that the majority $100(66.2 \%)$ provide proper privacy to the patient during bed bating but 51 (33.3\%) did not provide privacy. 92 $(60.9 \%)$ observed and $59(39.1 \%)$ not observed as offering bed pain/urinal during bed-bathing. Observation regarding item six which was "Remove gloves and discard in appropriate container. Wash hands. Put on clean gloves" and results revealed the $81(53.6 \%)$ observed and $70(46.4 \%)$ did not observed. The observation regarding item number seven of checklist which was "Place client in supine position near the side of the bed nearest you" and results revealed that the $79(52.3 \%)$ were observed and $76(50.3 \%)$ were not observed while giving bed bath to the patients.

The observation regarding item eight which is "Un-tuck bed linens" and results revealed that majority 85 $(56.3 \%)$ were observed and $66(43.7 \%)$ were not observed. The item nine was "Cover top sheet with a large towel. Ask the client to hold the towel in place; if unable, tuck under client's shoulders" and results revealed that 87 (57.6\%) were observed and majority 64 (42.4\%) not observed. It was also observed that in item ten "Remove top sheet without disturbing the towel and place in laundry basket at bedside" and the majority 93 (61.6\%) observed and 58 (38.4\%) did not observed. 91 (60.3\%) observed and 60 (39.7\%) not observed as remove client's gown or pajamas comfortly during bed-bathing. Observation regarding item twelve which was "Fill bath basin 
$2 / 3$ full of warm water $(1150 \mathrm{~F})$. Check temperature with inner aspect of arm." and results revealed the 93 $(61.6 \%)$ observed and $58(38.4 \%)$ did not observed. The observation regarding item number thirteen which was "Place a towel across the client's chest." and results revealed that the $85(56.3 \%)$ were observed and $66(43.7 \%)$ were not observed while giving bed bath to the patients. The observation regarding item fourteen which is "Wet washcloth and squeeze out excess water. Make a washcloth mitt" and results revealed that majority $84(55.6 \%)$ were observed and 67 (44.4\%) were not observed.

The item fifteen was "Wash eyes first. Start at inner corner and work out. Use different area of washcloth for each eye. Don't dangle the ends of the washcloth" and results revealed that $86(57 \%)$ were observed and majority 65 (43\%) not observed. It was also observed that in item sixteen "Wash, rinse, and dry face, ears, nose, and mouth" and the majority 76 (50.3\%) observed and 75 (49.7\%) did not observed. 89 (58.9 \%) observed and $62(41.1 \%)$ not observed as Wash, rinse, and dry neck during bed-bathing. Observation regarding item eighteen which was "Expose arm farther from you; place towel under arm up to axilla" and results revealed the $84(55.6 \%)$ observed and 67 (44.4\%) did not observed.

The observation regarding item number nineteen which was "Wash and rinse far shoulder, axilla, arm, and hand" and results revealed that the $104(68.9 \%)$ were observed and $47(31.1 \%)$ were not observed while giving bed bath to the patients. The observation regarding item twenty which is "Remove the basin and dry the client's arm, shoulder, and hand" and results revealed that majority $91(60.3 \%)$ were observed and $60(39.7 \%)$ were not observed. The item twenty-one was "Repeat steps 21-23 with arm closer to you." and results revealed that 94 (57\%) were observed and majority 57 (37.7\%) not observed. The observation regarding item number twenty-two which was "The In-Home Aide may perform fingernail care at this time." and results revealed that 94 (57\%) were observed and majority 57 (37.7\%) not observed while giving bed bath to the patients.

The observation regarding item twenty-three which is "Place towel across chest" and results revealed that majority 75 (49.7\%) were observed and 76 (50.3\%) were not observed. The item twenty-four was "Wash and rinse chest and breasts while lifting towel" and results revealed that $99(65.6 \%)$ were observed and majority 52 $(34.4 \%)$ not observed. The observation regarding item twenty-five which is "Dry skin thoroughly" and results revealed that majority $93(61,6 \%)$ were observed and $58(38.4 \%)$ were not observed. The item twenty-six was "Keep chest covered with towel." and results revealed that 85 (56.3\%) were observed and majority $66(43.7 \%)$ not observed.

Checklist regarding Bed-Bathing (Part 1)

Table 4

\begin{tabular}{|c|c|c|c|c|c|}
\hline SrNo & Check list items & $\begin{array}{l}\text { Observed } \\
\text { Frequency }\end{array}$ & Valid Percent & $\begin{array}{l}\text { Not observed } \\
\text { Frequency }\end{array}$ & Valid Percent \\
\hline 01 & Gather necessary equipment..... & 75 & $49.7 \%$ & 76 & $50.3 \%$ \\
\hline $\mathbf{0 2}$ & Wash your hands. Put on gloves. & 83 & $55 \%$ & 68 & $45 \%$ \\
\hline $\mathbf{0 3}$ & Explain what you are going to do. & 71 & $47 \%$ & 80 & $53 \%$ \\
\hline 04 & Provide privacy. & 100 & $66.2 \%$ & 51 & $33.8 \%$ \\
\hline 05 & Offer bedpan/urinal.............. & 92 & $60.9 \%$ & 59 & $39.1 \%$ \\
\hline 06 & Remove gloves and discard....... & 81 & $53.6 \%$ & 70 & $46.4 \%$ \\
\hline 07 & Place client in supine ............. & 79 & $52.3 \%$ & 72 & $47.7 \%$ \\
\hline 08 & Un-tuck bed linens. & 85 & $56.3 \%$ & 66 & $43.7 \%$ \\
\hline 09 & Cover top sheet with a ........... & 87 & $57.6 \%$ & 64 & $42.4 \%$ \\
\hline 10 & Remove top sheet without ....... & 93 & $61.6 \%$ & 58 & $38.4 \%$ \\
\hline 11 & Remove client's gown or pajamas. & 91 & $60.3 \%$ & 60 & $39.7 \%$ \\
\hline 12 & Fill bath basin $2 / 3 \ldots \ldots \ldots$ & 93 & $61.6 \%$ & 58 & $38.4 \%$ \\
\hline 13 & Place a towel across the .......... & 85 & $56.3 \%$ & 66 & $47.3 \%$ \\
\hline 14 & Wet washcloth and squeeze ....... & 84 & $55.6 \%$ & 67 & $44.4 \%$ \\
\hline 15 & Wash eyes first. Start at .......... & 86 & $57 \%$ & 65 & $43 \%$ \\
\hline 16 & Wash, rinse, and dry face,...$\ldots \ldots$ & 76 & $50.3 \%$ & 75 & $49.7 \%$ \\
\hline 17 & Wash, rinse, and dry neck......... & 89 & $58.9 \%$ & 62 & $41.1 \%$ \\
\hline 18 & Expose arm farther from ......... & 84 & $55.6 \%$ & 67 & $44.4 \%$ \\
\hline 19 & Wash and rinse far shoulder...... & 104 & $68.9 \%$ & 47 & $31.1 \%$ \\
\hline 20 & Remove the basin and dry....... & 91 & $60.3 \%$ & 60 & $39.7 \%$ \\
\hline 21 & Repeat steps 21-23 with ........... & 94 & $62.3 \%$ & 57 & $37.7 \%$ \\
\hline 22 & The In-Home Aide may......... & 94 & $62.3 \%$ & 56 & $37.1 \%$ \\
\hline 23 & Place towel across chest.......... & 75 & $49.7 \%$ & 76 & $50.3 \%$ \\
\hline 24 & Wash and rinse chest............. & 99 & $65.6 \%$ & 52 & $34.4 \%$ \\
\hline 25 & Dry skin thoroughly............ & 93 & $61.6 \%$ & 58 & $38.4 \%$ \\
\hline 26 & Keep chest covered with towel.... & 85 & $56.3 \%$ & 66 & $43.7 \%$ \\
\hline
\end{tabular}


Table 5 shows the frequency percentage of 25 items of checklist regarding bed-bathing and results revealed that mostly above $50 \%$ nurses have good practices and follow the standard guideline for bed bathing of admitted patient. Further the observation of nurses, having different level of education and also working in different department such as ward or critical care unit is varying to each other, such as the observation regarding twentyseven item of checklist and results revealed that the 67 (44.4\%) were observed as wash, rinse, and dry abdomen and $84(55.6 \%)$ were not observed while giving bed bath to the patients. The observation regarding item twentyeight which is "Change bath water in basin. Obtain a clean washcloth." and results revealed that majority 77 $(51 \%)$ were observed and $74(49 \%)$ were not observed. The results of item twenty-nine were $81(53.6 \%)$ were observed and 70 (46.4\%) not observed as Expose the farther leg; flex (bend) leg and place bath towel lengthwise under the leg up to the buttocks while going to give bath to the admitted patients. It was also observed that the majority $76(50.3 \%)$ provide proper privacy to the patient during bed bating but $75(49.7 \%)$ did not observed as wash and rinse leg and foot. 94 (62.3\%) observed and 57 (37.7\%) not observed as dry leg, foot, and in between toes.

Observation regarding item thirty-two which was "Repeat steps 32-34 on leg nearer you; cover client with bath blanket." and results revealed the 83 (55\%) observed and 68 (45\%) did not observed. The observation regarding item thirty-three which is "May perform toenail care at this time." and results revealed that majority 91 $(60.3 \%)$ were observed and $60(39.7 \%)$ were not observed. The results of item thirty-four were $93(61.6 \%)$ were observed and $58(38.4 \%)$ not observed as place the towel and washcloth in a laundry basket and get clean ones while going to give bath to the admitted patients.

The results of item thirty-five were $81(53.6 \%)$ were observed and 70 (46.4\%) not observed as Change bath water in basin. Obtain a clean washcloth while going to give bath to the admitted patients. It was also observed that the majority 85 (56.3\%) observed to ask or assist the client to turn on his side with back towards you, to the patient during bed bating but $66(43.7 \%)$ did not observed. $76(50.3 \%)$ observed and $75(49.7 \%)$ not observed as Fold a towel over the client's side to expose his back and buttocks; place clean towel parallel to client's back. Observation regarding item thirty-eight which was "Wash, rinse, and dry the client's back and buttocks" and results revealed the $82(54.3 \%)$ observed and $69(45.7 \%)$ did not observed. The results of item thirty-nine were $88(58.3 \%)$ were observed and $63(41.7 \%)$ not observed as Give backrub using warmed lotion while going to give bath to the admitted patients.

It was also observed that the majority $88(58.3 \%)$ observed to turn client to back; place clean towel under buttocks to the patient during bed bating but 63 (41.7\%) did not observed. $95(62.9 \%)$ observed and $56(37.1 \%)$ not observed as If client is able, provide wash cloth, soap, and towel and instruct him to wash and dry peri area. Observation regarding item forty-two which was "If the client is unable, wash peri area from front to back" and results revealed the $82(54.3 \%)$ observed and 69 (45.7\%) did not observed. The observation regarding item fortythree which is "Place dirty linen in appropriate container" and results revealed that majority $86(57 \%)$ were observed and 65 (43\%) were not observed. The results of item forty-four were $99(65.6 \%)$ were observed and 52 (34.4\%) not observed as remove and dispose of gloves, wash hands while going to give bath to the admitted patients. The observation regarding item forty-five which is "If client did own peri care, provide fresh water for client to wash hands" and results revealed that majority $81(53.6 \%)$ were observed and $70(46.4 \%)$ were not observed.

The results of item forty-six were 91 (60.3\%) were observed and 60 (39.7\%) not observed as Apply warmed lotion and deodorant as needed while going to give bath to the admitted patients. The observation regarding item forty-seven which is "Put clean clothing on client without exposing him." and results revealed that majority 75 $(49.7 \%)$ were observed and $76(50.3 \%)$ were not observed. The results of item forty-eight were $108(71.5 \%)$ were observed and $43(28.5 \%)$ not observed as remove, clean, and store equipment while going to give bath to the admitted patients.

The observation regarding item forty-nine which is "Wash your hands" and results revealed that majority 92 $(60.9 \%)$ were observed and $59(39.1 \%)$ were not observed. The results of item fifty were $93(61.6 \%)$ were observed and 58 (38.4\%) not observed as Make the client comfortable while going to give bath to the admitted patients. The results of item fifty-one were $76(50.3 \%)$ were observed and $75(49.7 \%)$ not observed as record observations and report anything unusual to nurse/supervisor while going to give bath to the admitted patients. 
Checklist regarding Bed-Bathing (Part 2)

Table 5

\begin{tabular}{|c|c|c|c|c|c|}
\hline SrNo & Check list items & $\begin{array}{l}\text { Observed } \\
\text { Frequency }\end{array}$ & $\begin{array}{c}\text { Valid } \\
\text { Percent }\end{array}$ & $\begin{array}{c}\text { Not } \\
\text { observed } \\
\text { Frequency }\end{array}$ & $\begin{array}{c}\text { Valid } \\
\text { Percent }\end{array}$ \\
\hline 27 & Wash, rinse, and dry... & 67 & $44.4 \%$ & 84 & $55.6 \%$ \\
\hline 28 & Change bath water in... & 77 & $51 \%$ & 74 & $49 \%$ \\
\hline 29 & Expose the farther leg... & 81 & $53.6 \%$ & 70 & $46.4 \%$ \\
\hline 30 & Wash and rinse leg... & 76 & $50.3 \%$ & 75 & $49.7 \%$ \\
\hline 31 & Dry leg, foot, and in ... & 94 & $62.3 \%$ & 57 & $37.7 \%$ \\
\hline 32 & Repeat steps $32-34$ on... & 83 & $55 \%$ & 68 & $45 \%$ \\
\hline 33 & May perform toenail... & 91 & $60.3 \%$ & 60 & $39.7 \%$ \\
\hline 34 & Place the towel... & 93 & $61.6 \%$ & 58 & $38.4 \%$ \\
\hline 35 & Change bath water... & 81 & $53.6 \%$ & 70 & $46.4 \%$ \\
\hline 36 & Ask or assist the client... & 85 & $56.3 \%$ & 66 & $43.7 \%$ \\
\hline 37 & Fold a towel over the... & 76 & $50.3 \%$ & 75 & $49.7 \%$ \\
\hline 38 & Wash, rinse, and dry... & 82 & $54.3 \%$ & 69 & $45.7 \%$ \\
\hline 39 & Give backrub using ... & 88 & $58.3 \%$ & 63 & $41.7 \%$ \\
\hline 40 & Turn client to back.... & 88 & $58.3 \%$ & 63 & $41.7 \%$ \\
\hline 41 & If client is able, provide... & 95 & $62.9 \%$ & 56 & $37.1 \%$ \\
\hline 42 & If the client is unable... & 82 & $54.3 \%$ & 69 & $45.7 \%$ \\
\hline 43 & Place dirty linen in...... & 86 & $57 \%$ & 65 & $43 \%$ \\
\hline 44 & Remove and dispose of... & 99 & $65.6 \%$ & 52 & $34.4 \%$ \\
\hline 45 & If client did own peri... & 81 & $53.6 \%$ & 70 & $46.4 \%$ \\
\hline 46 & Apply warmed lotion... & 91 & $60.3 \%$ & 60 & $39.7 \%$ \\
\hline 47 & Put clean clothing on... & 75 & $49.7 \%$ & 76 & $50.3 \%$ \\
\hline 48 & Remove, clean, and.... & 108 & $71.5 \%$ & 43 & $28.5 \%$ \\
\hline 49 & Wash your hands... & 92 & $60.9 \%$ & 59 & $39.1 \%$ \\
\hline 50 & Make the client.... & 93 & $61.6 \%$ & 58 & $38.4 \%$ \\
\hline 51 & Record observations... & 76 & $50.3 \%$ & 75 & $49.7 \%$ \\
\hline
\end{tabular}

Table 6 shows that the statistics (mean, median, mode and standard deviation) of 26 items of checklist regarding bed bathing and results revealed that the highest mean value is 1.69 of item nineteen which is "Wash and rinse far shoulder, axilla, arm, and hand" and comparatively lowest mean value is 1.47 for item three which is "Explain what you are going to do". The mean value for others item is between 1.47-1.69 respectively. Median and mode value of most of items is 2 and lowest is 1 . Standard deviation value .502 is highest and comparatively .465 is low.

Statistics Checklist regarding Bed-Bathing (Part 1)

Table 6

\begin{tabular}{|c|c|c|c|c|c|c|}
\hline SrNo & Check list items & $\mathbf{N}$ & Mean & Median & Mode & $\begin{array}{c}\text { Std. } \\
\text { Deviation }\end{array}$ \\
\hline 01 & Gather necessary equipment.... & 151 & 1.50 & 1.00 & 1 & .502 \\
\hline $\mathbf{0 2}$ & Wash your hands. Put on gloves. & 151 & 1.55 & 2.00 & 2 & .499 \\
\hline 03 & Explain what you are going to do. & 151 & 1.47 & 1.00 & 1 & .501 \\
\hline 04 & Provide privacy. & 151 & 1.66 & 2.00 & 2 & .475 \\
\hline 05 & Offer bedpan/urinal............. & 151 & 1.61 & 2.00 & 2 & .490 \\
\hline 06 & Remove gloves and discard....... & 151 & 1.54 & 2.00 & 2 & .500 \\
\hline 07 & Place client in supine...$\ldots \ldots \ldots$ & 151 & 1.52 & 2.00 & 2 & .501 \\
\hline 08 & Un-tuck bed linens. & 151 & 1.56 & 2.00 & 2 & .498 \\
\hline 09 & Cover top sheet with a ......... & 151 & 1.58 & 2.00 & 2 & .496 \\
\hline 10 & Remove top sheet without ....... & 151 & 1.62 & 2.00 & 2 & .488 \\
\hline 11 & Remove client's gown or pajamas. & 151 & 1.60 & 2.00 & 2 & .491 \\
\hline 12 & Fill bath basin $2 / 3 \ldots \ldots \ldots$ & 151 & 1.62 & 2.00 & 2 & .488 \\
\hline 13 & Place a towel across the .......... & 151 & 1.56 & 2.00 & 2 & .498 \\
\hline 14 & Wet washcloth and squeeze ....... & 151 & 156 & 2.00 & 2 & .498 \\
\hline 15 & Wash eyes first. Start at .......... & 151 & 1.57 & 2.00 & 2 & .497 \\
\hline 16 & Wash, rinse, and dry face, $\ldots \ldots \ldots$ & 151 & 1.50 & 2.00 & 2 & .502 \\
\hline 17 & Wash, rinse, and dry neck........ & 151 & 1.59 & 2.00 & 2 & .494 \\
\hline
\end{tabular}




\begin{tabular}{|c|c|c|c|c|c|c|}
\hline SrNo & Check list items & $\mathbf{N}$ & Mean & Median & Mode & $\begin{array}{c}\text { Std. } \\
\text { Deviation }\end{array}$ \\
\hline 18 & Expose arm farther from & 151 & 1.56 & 2.00 & 2 & .498 \\
\hline 19 & Wash and rinse far shoulder....... & 151 & 1.69 & 2.00 & 2 & .465 \\
\hline 20 & Remove the basin and dry........ & 151 & 1.60 & 2.00 & 2 & .491 \\
\hline 21 & Repeat steps $21-23$ with ... & 151 & 1.62 & 2.00 & 2 & .486 \\
\hline 22 & The In-Home Aide may......... & 151 & 1.63 & 2.00 & 2 & .485 \\
\hline 23 & Place towel across chest.......... & 151 & 1.50 & 1.00 & 1 & .502 \\
\hline 24 & Wash and rinse chest............ & 151 & 1.66 & 2.00 & 2 & .477 \\
\hline 25 & Dry skin thoroughly............ & 151 & 1.62 & 2.00 & 2 & .488 \\
\hline 26 & Keep chest covered with towel.... & 151 & 1.56 & 2.00 & 2 & .498 \\
\hline
\end{tabular}

Table 7 shows that the statistics (mean, median, mode and standard deviation) of 25 items of checklist regarding bed bathing and results revealed that the highest mean value is 1.72 of item forty-eight which is "Remove, clean, and store equipment" and comparatively lowest mean value is 1.44 for item twenty-seven which is "Wash, rinse, and dry abdomen.". The mean value for others item is between 1.44-1.72 respectively. Median and mode value of most of items is 2 and lowest is 1 . Standard deviation value .502 is highest and comparatively .453 is low.

Statistics Checklist regarding Bed-Bathing (Part 2)

Table 7

\begin{tabular}{|c|c|c|c|c|c|c|}
\hline SrNo & Check list items & $\mathbf{N}$ & Mean & Median & Mode & $\begin{array}{c}\text { Std. } \\
\text { Deviation } \\
\end{array}$ \\
\hline 27 & Wash, rinse, and dry abdomen.... & 151 & 1.44 & 1.00 & 1 & .498 \\
\hline 28 & Change bath water in basin....... & 151 & 1.51 & 2.00 & 2 & .502 \\
\hline 29 & Expose the farther leg....... & 151 & 1.54 & 2.00 & 2 & .500 \\
\hline 30 & Wash and rinse leg and foot.... & 151 & 1.50 & 2.00 & 2 & .502 \\
\hline 31 & Dry leg, foot, and in ....... & 151 & 1.62 & 2.00 & 2 & .486 \\
\hline 32 & Repeat steps 32-34 on leg ....... & 151 & 1.55 & 2.00 & 2 & .499 \\
\hline 33 & May perform toenail care at..... & 151 & 1.60 & 2.00 & 2 & .491 \\
\hline 34 & Place the towel and washcloth .... & 151 & 1.62 & 2.00 & 2 & .488 \\
\hline 35 & Change bath water in basin...... & 151 & 1.54 & 2.00 & 2 & .500 \\
\hline 36 & Ask or assist the client to turn .... & 151 & 1.56 & 2.00 & 2 & .498 \\
\hline 37 & Fold a towel over the client's...... & 151 & 1.50 & 2.00 & 2 & .502 \\
\hline 38 & Wash, rinse, and dry the.......... & 151 & 1.54 & 2.00 & 2 & .500 \\
\hline 39 & Give backrub using ........... & 151 & 1.58 & 2.00 & 2 & .495 \\
\hline 40 & Turn client to back; place......... & 151 & 1.58 & 2.00 & 2 & .495 \\
\hline 41 & If client is able, provide wash.... & 151 & 1.63 & 2.00 & 2 & .485 \\
\hline 42 & If the client is unable........... & 151 & 1.54 & 2.00 & 2 & .500 \\
\hline 43 & Place dirty linen in............. & 151 & 1.57 & 2.00 & 2 & .497 \\
\hline 44 & Remove and dispose of......... & 151 & 1.66 & 2.00 & 2 & .477 \\
\hline 45 & If client did own peri care......... & 151 & 1.54 & 2.00 & 2 & .500 \\
\hline 46 & Apply warmed lotion............ & 151 & 1.60 & 2.00 & 2 & .491 \\
\hline 47 & Put clean clothing on............ & 151 & 1.50 & 1.00 & 1 & .502 \\
\hline 48 & Remove, clean, and store......... & 151 & 1.72 & 2.00 & 2 & .453 \\
\hline 49 & Wash your hands........... & 151 & 1.61 & 2.00 & 2 & .490 \\
\hline 50 & Make the client comfortable.... & 151 & 1.62 & 2.00 & 2 & .488 \\
\hline 51 & Record observations............ & 151 & 1.50 & 2.00 & 2 & .502 \\
\hline
\end{tabular}

\section{DISCUSSION}

Vulnerable skin is more prone to damage, and infection. Bathing the critically ill can result in significant variations such as extremely dry skin, greater nursing time, and the potential for colonization of the skin and the spread of microorganism. Critically ill patients are unable to provide self-care and critically ill patients are unable to perform self-care because of many reasons such as decrease level of consciousness, sedation and mechanical ventilation (Grealy \& Chaboyer, 2011; Petlin et al., 2014). Frequency, timing and duration bed-bath in ICUs in the current study, the majority of nurses performed bed bath three times/day. Little literature exists on the frequency of bed-bath. However, Coyer et al (Peate \& Lane, 2015)

Conducted an exploratory study on bed-bathing performed to critically ill patients, and showed that $37.5 \%$ of all bed baths were routine daily baths. It is acceptable that nurses provide bed-bath for critically ill patients at 
least once daily. However, bed-bath should be performed according to patients' needs such as for comfort to reduce anxiety, or for cleanliness to respond to diaphoresis, or incontinence. In the current study, patients had bed-bath once/shift (12 or 8 hrs.); nurses were performing bed-bath once/shift as a nursing routine and according to ICU policy. Bed-bath is associated with an increase in oxygen consumption. The current study revealed that nurses took into consideration patients' physiologic tolerance to bathing. This result is in agreement with the AACN guidelines who recommends that patients' physiologic tolerance to the activity should be considered when determining optimal time for bed-bath (Makic, Rauen, Watson, \& Poteet, 2014).

On weaning trial days, the researchers found a longer weaning trial (average 3 hours) when the bath is given during weaning. During bed-bath, patients may remain in supine position, which may decrease ventilation and causes hypoxemia. In addition, during bathing, nurses may be unable to observe patients' hemodynamic state accurately. Bed-bath may be performed according to the suitability of nursing routine or workload without considering patients hygiene needs. In the current study, time of bed-bath for patients was at 6 a.m., 1 p.m. and 6 p.m. and the majority of patients had bed-bath at 6 a.m. and 6 p.m. However, Coyer et al. found that a routine bath was given between 2 a.m. and 6 a.m. in 30\% of bed-bath episodes (Coyer, O'Sullivan, \& Cadman, 2011).

Many studies did not present the duration of bed bathing. From the current study findings, it was noted that, eighty percent of bed- bath performed by nurses took 15-20 min. However, based on the records of some studies that published the bathing time variable, the global average total bathing time was calculated as 20 minutes and 14 seconds (El-Soussi \& Asfour, 2016; Lima \& Lacerda, 2010).

The quality and skin microbial scores were similar, but the prepackaged bed-bath resulted in the use of significantly less product, a reduction in time to gather supplies and perform the bath, lower cost, and higher nurse satisfaction (O'Horo, Silva, Munoz-Price, \& Safdar, 2012). However, the results in this study revealed that water was not changed during most traditional baths, and washcloths were reused from contaminated regions. However, a study compared fifty traditional baths.

Nurses in the study had higher satisfaction with the CHG-impregnated cloths produced colony count reduction on the skin when compared with soap-and-water bed-bath and a significant reduction in CLABSIs was demonstrated with $\mathrm{CHG}$ bed-bath. A study comparing $\mathrm{CHG}$ cloth bed-bath with non-antimicrobial basin-less cloth bed bath showed, the rate of multidrug resistance organisms (MDRO) acquisition, UTIs and hospitalassociated bloodstream infections was lower 5.10 with $\mathrm{CHG}$ cloth bed-bath than with non-antimicrobial cloth bed-bath (Hines et al., 2015).

In the current study, an emollient was not applied for all patients after bathing. In a study of bed-bath practices, the researchers found that $64.4 \%$ of patients did not receive an emollient after a basin bath. The washcloths used mainly have rough surfaces; therefore, they increase the amount of trans-epidermal water loss and increase dry skin. Some patients had dry skin and need an emollient after bathing; the results of the current study may be due to lack of resources (Oranje, Ordonez, De Raeve, Spierings, \& van der Wouden, 2016).

Conclusion: This study has described an important basic nursing care that is bed-bath practice in critically ill patient. Although, bed-bath is a routine nursing procedure, critical care nurses in the current study had poor skills and practices regarding it. This study has implications for clinical practice and nursing research. Bed-bath is a routine nursing care; many nurses understand that bathing is just for cleaning. Therefore, Inservice training program should be conducted for nurses regarding putting priority of nursing care, determining timing, frequency for the bed-bath and prevention of infections during bathing.

Recommendation: It is important for the organization to develop a protocol for bed-bath of critically ill patients to be applicable in the settings. Further research is necessary to determine the appropriate timing of bed-bath and other patient care activities. Studies are needed to determine the effect of bed-bath on patients' outcomes such as sleep disturbance, infection and other stressors in ICU. There is a need for further research on the efficacy of disposable bed-bath products such as pre-packaged cloths.

\section{Limitation/ Scope of the study}

- Investigation discoveries will be restricted and can't be summed up generally that the little example and chose from one topographical zone in Pakistan.

- The extent of the investigation will be likewise restricted not utilized benchmark group.

\section{References}

Badran, I. G. (1995). Knowledge, attitude and practice the three pillars of excellence and wisdom: a place in the medical profession.

Büyükyılmaz, F., \& Şendir, M. (2017). Opinions of intensive care nurses: traditional or disposable wipes bed bath? A quasi-qualitative and cost analysis study. International Journal of Nursing \& Clinical Practices, 2017.

Cowdell, F., Jadotte, Y. T., Ersser, S. J., Danby, S., Lawton, S., Roberts, A., \& Dyson, J. (2020). Hygiene and emollient interventions for maintaining skin integrity in older people in hospital and residential care settings. Cochrane Database of Systematic Reviews(1). 
Coyer, F. M., O'Sullivan, J., \& Cadman, N. (2011). The provision of patient personal hygiene in the intensive care unit: a descriptive exploratory study of bed-bathing practice. Australian Critical Care, 24(3), 198-209.

Dias, J. A. A., Souza, D. M. d., Azevedo, B. D. S., Andrade, I. S., \& Nery, P. Y. G. (2016). The bed bath according to the undergraduate nursing students' perspective. Revista de Pesquisa: Cuidado é Fundamental Online, 8(4), 5087-5094.

Dougherty, L., \& Lister, S. (2015). The Royal Marsden manual of clinical nursing procedures: John Wiley \& Sons.

El-Soussi, A. H., \& Asfour, H. I. (2016). Examining bed-bath practices of critically ill patients. Journal of nursing education and practice, 6(12), 1-11.

Ette, L., \& Gretton, M. (2019). The significance of facial shaving as fundamental nursing care. Nursing Times, $115(1), 40-42$.

Grealy, B., \& Chaboyer, W. (2011). Essential nursing care of the critically ill patient. ACCCN's Crit Care Nurs, 105.

Groven, F. M., Zwakhalen, S. M., Odekerken-Schröder, G., Joosten, E. J., \& Hamers, J. P. (2017). How does washing without water perform compared to the traditional bed bath: a systematic review. BMC geriatrics, 17(1), 31.

Hema Priya, S., Nandi, P., Seetharaman, N., Ramya, M., Nishanthini, N., \& Lokeshmaran, A. (2017). A study of menstrual hygiene and related personal hygiene practices among adolescent girls in rural Puducherry. International Journal of Community Medicine and Public Health, 4(7), 2348.

Hines, A. G., Nuss, S., Rupp, M. E., Lyden, E., Tyner, K., \& Hewlett, A. (2015). Chlorhexidine bathing of hospitalized patients: beliefs and practices of nurses and patient care technicians, and potential barriers to compliance. Infection Control \& Hospital Epidemiology, 36(8), 993-994.

Lawton, S. (2016). Emollients and ageing skin: optimising effectiveness and safety. British Journal of Nursing, 25(11), 596-598.

Lima, D. V. M. d., \& Lacerda, R. A. (2010). Hemodynamic oxygenation effects during the bathing of hospitalized adult patients critically ill: systematic review. Acta Paul Enferm., 23(2), 278-285.

Makic, M. B. F., Rauen, C., Watson, R., \& Poteet, A. W. (2014). Examining the evidence to guide practice: challenging practice habits. Critical care nurse, 34(2), 28-45.

Manderson, L. (2018). Humans on show: performance, race and representation. Critical African Studies, 10(3), 257-271.

Noto, M. J., Domenico, H. J., Byrne, D. W., Talbot, T., Rice, T. W., Bernard, G. R., \& Wheeler, A. P. (2015). Chlorhexidine bathing and health care-associated infections: a randomized clinical trial. Jama, 313(4), 369378.

O'Horo, J. C., Silva, G. L., Munoz-Price, L. S., \& Safdar, N. (2012). The efficacy of daily bathing with chlorhexidine for reducing healthcare-associated bloodstream infections: a meta-analysis. Infection Control \& Hospital Epidemiology, 33(3), 257-267.

Oranje, A. P., Ordonez, C., De Raeve, L., Spierings, M., \& van der Wouden, J. C. (2016). Emollients for eczema. Cochrane database of systematic reviews, $2016(8)$, CD008304.

Peate, I., \& Lane, J. (2015). Bed bathing: how good cleaning turns into great care. British Journal of Healthcare Assistants, 9(4), 174-178.

Petlin, A., Schallom, M., Prentice, D., Sona, C., Mantia, P., McMullen, K., \& Landholt, C. (2014). Chlorhexidine gluconate bathing to reduce methicillin-resistant Staphylococcus aureus acquisition. Critical care nurse, 34(5), 17-24.

Sturgeon, L. P., Garrett-Wright, D., Lartey, G., Jones, M. S., Bormann, L., \& House, S. (2019). A descriptive study of bathing practices in acute care facilities in the United States. American journal of infection control, 47(1), 23-26.

Sunley, K., Gallagher, R., Reidy, M. P., \& Dunn, H. (2018). Essential practice for infection prevention and control: RCN guidance for nursing staff, 2/2. British Journal of Healthcare Assistants, 12(1), 28-33.

Wigglesworth, N. (2019). Infection control 3: use of disposable gloves and aprons. Nursing Times, 115(7), 34-36. 